\title{
SOLIDÃo E RELAÇõES AFETIVAS NA ERA DA TÉCNICA *
}

\author{
Roberto Novaes de Sá ${ }^{\star}$, Cristine Monteiro Mattar ${ }^{\star \star}$ \\ e Joelson Tavares Rodrigues ${ }^{\star \star \star}$
}

\begin{abstract}
RESUMO
Este artigo tem por objetivo a reflexão, sob o enfoque da fenomenologiahermenêutica, acerca de um tema recorrente para a clínica psicoterápica: a solidão e as relações afetivas. A relação entre solidão e isolamento e a angústia frente à necessidade de controle e de segurança nos relacionamentos, serão analisados à luz do pensamento do filósofo Martin Heidegger, e de outros autores como Medard Boss, enquanto possibilidades de sentido que compõem o horizonte histórico do homem moderno. Neste contexto o papel desempenhado pela psicoterapia não será somente o ajustamento, mas se constituirá em um espaço de meditação, em que se farão presentes outras possibilidades de ser no mundo com o outro.
\end{abstract}

Palavras-chave: Solidão. Relações afetivas. Cuidado.

\section{LONELINESS AND AFFECTIVE RELATIONSHIPS IN TECHNICAL ERA}

\begin{abstract}
This paper aims to reflect, under a phenomenological-hermeneutic approach, about a recured complain in psychoterapic setting: loneliness and affective relationships. The connection between loneliness, isolation and anxiety with the necessity of control and security on relationships were analysed. For this we used Martin Heidegger's philosophical thought. We concluded these feelings are possibilities of meaning that constitute the historic experience of modern man. This way, psychotherapy will not intent only an adjustment but will be a setting of medidation, where other possibilities of being in the world with others will be present.

Keywords: Loneliness. Affective relationship. Care.

* Trabalho desenvolvido na linha de pesquisa "Fenomenologia-hermenêutica e clínica psicoterápica", realizada no Departamento de Psicologia da UFF, coordenada pelo Prof. Dr. Roberto Novaes de Sá.

E-mail: roberto_novaes@terra.com.br

$\star \star$ Professor do Programa de Mestrado em Estudos da Subjetividade do Departamento de Psicologia da UFF. Instituto de Ciências Humanas e Filosofia Campus do Gragoatá, bloco O, sala 332 Niterói RJ - Cep: 24210350.

Email: fenomenologia_hermeneutica_uff@hotmail.com

$\star \star \star$ Mestre em Psicologia pela UFF, Psicoterapeuta.

$\star \star \star \star$ Médico Psiquiatra, Mestre em Psicologia pela UFF, Doutorando em Psicologia na UFRJ.
\end{abstract}

Revista do Departamento de Psicologia - UFF, v. 18 - n. 2, p. 111-124, Jul./Dez. 2006 


\section{SOLIDÃo E ISOLAMENTO}

Amar também é bom: porque o amor é dificil. O amor de duas criaturas humanas talvez seja a tarefa mais dificil que nos foi imposta, a maior e última prova, a obra para a qual todas as outras são apenas uma preparação.

(RILKE, 1989, p. 55)

Estas palavras foram dirigidas pelo escritor tcheco Rainer Maria Rilke ao jovem Franz Kappus. Na carta, Rilke também fala sobre a solidão. Percebe algo em Kappus que deseja sair dela, e sugere que este, ao contrário, se sirva tranqüilamente deste desejo como um instrumento para estendê-la mais, até que ocupe um vasto território. "É bom estar só, porque a solidão é difícil". Para Rilke, os homens resolveram tudo pelo lado mais fácil, através de convenções, então propõe ao jovem poeta ligar-se ao mais difícil.

A solidão é percebida hoje como um mal que deve e pode ser evitado a qualquer custo, basta que se tenha competência para isto. Estar sozinho e estar isolado, apartado do outro por uma distância intransponível, são considerados sinônimos. Ao mesmo tempo, o relacionamento amoroso nos moldes românticos é desejado como o grande bem, a meta de felicidade que ofusca todas as outras, ou, ao contrário, repudiado, porque visto como fórmula de sofrimento, o que se traduz em condutas que passamos a chamar de insegurança, medo de envolver-se, de comprometer-se com o outro, de ser rejeitado. Assim, procura-se não se vincular a ninguém, trocando de parceiro antes que isto ocorra.

Esta questão surge nos consultórios de psicoterapia sob a forma de queixas e preocupações semelhantes, embora emitidas por pessoas diferentes. Os temas se repetem: ciúmes, tentativa de exercer o controle e assegurar-se da permanência do outro, temor da traição e do abandono; queixa pelo modo como se dão hoje os relacionamentos amorosos, avessos ao compromisso e à previsibilidade; a escolha do par amoroso por aquilo que pode trazer em termos de "vantagens", status, seja pela aparência, pelos bens que possui etc.; e, finalmente, a afirmação de estar protegido tendo ao lado o par amoroso, cuja ausência traz a sensação de "vazio", de "aperto no peito", de angústia. Todos estes, dentre outros, têm como pano de fundo a solidão e a tentativa de disponibilizar o outro para aplacá-la. Por ser uma questão recorrente para a clínica psicoterápica, impõe-se como importante tema para reflexão.

A idéia de que estar só é estar irremediavelmente apartado do outro é partilhada também por alguns psicoterapeutas, dentre eles, Irwin D. Yalom, cujas idéias podem ser consideradas até certo ponto representativas da perspectiva existencial em psicoterapia. Para Yalom (1996) a solidão é uma das condições, um dos "dados" (givens) da existência, tão inevitável quanto os demais: a morte, a liberdade e a ausência de significado ou sentido óbvio para a vida. Contra ela tentar-seá muitas vezes usar o outro como um escudo. Diz ele:

"O isolamento existencial, um terceiro dado, refere-se à lacuna intransponível entre o eu e os outros, uma lacuna que existe 
mesmo na presença de relacionamentos interpessoais profundamente gratificantes. Estamos isolados não apenas dos outros seres, mas, na extensão em que constituímos nosso mundo, também do mundo". (YALOM, 1996, p. 10).

Yalom (1996) distingue o isolamento existencial do que se costuma chamar vulgarmente de solidão. Esta é, em geral, entendida não como uma condição, mas sim como "isolamento interpessoal", ou seja, o que ocorre quando não se possui as habilidades sociais ou o estilo de personalidade que permite interações sociais íntimas, estando, portanto, em poder do sujeito reverter ou não tal circunstância.

Segundo Yalom os relacionamentos fracassam quando são tentadas falsas soluções para o intransponível isolamento existencial, ou seja, quando se usa o outro como um escudo contra a solidão ao invés de importar-se com ele. Apaixonando-se, a pessoa busca a fusão com o outro, desviando-se da autoconsciência que traz ansiedade ao elevado preço de perder a si mesma.

Embora concordando com o autor no que se refere à solidão como condição inalienável da existência, pela qual respondemos por nós mesmos, pretende-se colocar em questão a idéia de que ela seja fruto de uma "lacuna intransponível" que nos tornaria irremediavelmente apartados do mundo e do outro.

Esta idéia pressupõe o homem como sujeito encapsulado, interioridade separada do mundo, sobre o qual se volta para conhecer, explicar, intervir, controlar e explorar.

\section{O HOMEM COMO "SER-NO-MUNDO-COM-O-OUTRO"}

Para o pensamento de Martin Heidegger, essa concepção do homem como sujeito é apenas uma das possibilidades históricas do homem realizar a experiência do sentido de si-mesmo, não traduzindo apropriadamente sua estrutura ontológica, isto é, seu modo de ser mais próprio.

Heidegger (1989) denomina com o termo Dasein (Ser-aí) este ente que nós mesmos somos e que apresenta uma diferença radical com relação aos entes que não têm o modo de ser do homem. Na concepção deste filósofo, o homem não possui uma essência positiva determinada a priori, antes, o que ele é, seu ser, está sempre em jogo no seu existir. Não se trata apenas de distinguir o homem dos outros entes através de alguma característica essencial, como o pensamento ou a linguagem, que seria adicionada a uma substância comum. Ou seja, não é suficiente para a compreensão do modo de ser deste ente, distinguir entre uma res extensa e uma res cogitans. O ser do homem não é res alguma e, portanto, nunca é passível de qualquer objetivação como sujeito ou subjetividade. $\mathrm{O}$ Dasein é a própria abertura de sentido na qual pode vir à luz o ser dos entes que se dão ao seu encontro.

A expressão "ser-no-mundo" traduz a unidade estrutural ontológica da existência. O Dasein é "mundano", co-originário ao "mundo", diferenciando-se dos entes simplesmente dados, "intramundanos", mas destituídos de mundo. Por exemplo, pedras, árvores e animais estão no mundo, mas não têm mundo, isto é, não 
são aberturas de sentido, não se podendo dizer deles que "existem". Mundo é abertura de sentido, contexto de significação, linguagem.

O ente que é segundo o modo de "ser-no-mundo", não é encerrado em si mesmo, numa interioridade psíquica, estando sempre num contexto relacional. Ainda que esteja no isolamento, é "ser-com", co-presença. Uma mesa ou uma porta não podem ser solitárias no mesmo sentido que um homem, pois seu modo de ser é simplesmente dado. Apenas o ente cujo modo de ser é originariamente "ser-no-mundo-com-o-outro", possui a possibilidade de ser solitário. É nesse "serno-mundo-com-os-outros" que aparece o sentido como desvelamento dos entes que lhe vêm ao encontro. O termo "cuidado" (Sorge) é usado por Heidegger (1989) para designar a característica ontológica do Dasein de ser sempre em relação com outros entes. O modo das relações com os "entes cujo modo de ser é simplesmente dado" (Vorhandenheit) foram denominados por Heidegger de "ocupação" (Besorgen) e o modo das relações com os entes dotados do seu modo de ser de "preocupação" (Fürsorge).

O modo mais imediato do Dasein se relacionar com os outros entes se dá sempre através da ocupação no manuseio e uso, subordinados ao "ser-para" dos instrumentos, ou seja, está sempre referido a um contexto de significância, mundo, em que predomina o uso ou utilidade. Embora o Dasein seja essencialmente abertura de possibilidades de sentido, de início e na maior parte das vezes, apreende a si mesmo e aos outros, a partir daquele contexto instrumental, como um ente cujo modo de ser fosse simplesmente dado. No caso da época moderna, o Dasein encontra de início a si mesmo como "sujeito", "egoidade", "individualidade", "interioridade" em contraposição ao mundo "exterior" e separado dos outros sujeitos, com os quais pode estabelecer apenas relações intersubjetivas.

Entretanto, justamente quando a referência instrumental é perturbada por algum obstáculo, ou seja, quando o instrumento falha, pode anunciar-se o "mundo". É a partir dos imprevistos que o Dasein é lançado numa perspectiva em que aquilo cujo sentido era simplesmente dado revela-se como "estando em jogo", como dependente de um tecido mais amplo e complexo de sentido, o mundo. Tal "estranhamento" é, de início e quase sempre, experienciado como um angustiante vazio de sentido e não como liberdade de possibilidades. Daí o fato de que o Dasein tende, em seu modo cotidiano e mediano, a desviar-se dele, aferrando-se, na medida em que lhe é possível, às interpretações "já dadas" e impessoais sobre si mesmo e sobre outros entes. No caso da convivência cotidiana, este "desviarse" significa, antes de tudo e na maior parte das vezes, reduzir o "ser-com-ooutro" ao mundo das ocupações, empenhando-se no controle, na certeza e na segurança. Nesse modo mediano de "cuidado", imperam a dependência e a dominação, ainda que não apropriadas tematicamente e encobertas por discursos impessoais de valorização dos "afetos" e da "necessidade do amor".

Para melhor compreender a estrutura dos modos contemporâneos de "preocupação", "cuidado" relativo aos outros "existentes", é imperativo uma aproximação temática do horizonte histórico a partir do qual se desvelam os sentidos dos entes nesta época denominada por Heidegger (2002) como "a era da técnica". 


\section{A Questão da TÉCNICA}

No ensaio intitulado A questão da técnica (Die frage nach der technik, 19491953; HEIDEGGER, 2002) propõe o questionamento da técnica, não para condenála, nem para oferecer uma alternativa que a substitua, mas sim para estabelecer com ela um relacionamento mais livre, de abertura à sua essência, pois afirmandoa ou negando-a apaixonadamente, a ela mais nos aprisionamos.

Heidegger (2002) parte da definição usual da técnica, que é a de ser um meio para um fim e uma atividade do homem, determinação instrumental e antropológica. Embora correta, esta determinação não mostra a essência da técnica, porém, ao ser indagada, permite chegar até ela. Ao indagar a instrumentalidade, meio para um fim, chega-se à causalidade, à idéia de causa e efeito. $\mathrm{Na}$ modernidade a causa é considerada o que se faz para provocar um efeito, para obter resultados, o que remete à causa eficiente, uma das quatro causas enunciadas pelos gregos: causa material, causa formal, causa final e causa eficiente. Heidegger dá como exemplo a confecção de uma taça de prata para o culto do sacrifício, onde as quatro causas seriam respectivamente: a prata, a forma de taça, o culto e o ourives. No entanto, ressalta que, para Aristóteles, a quem remonta a doutrina das quatro causas, a causa eficiente, como as demais, não remetia à eficiência e eficácia de um fazer, mas todas eram formas de "responder por" e "dever". Assim, o cálice pronto deve-se à prata, à forma, ao culto, e ao ourives, que por ele respondem, este último, porém, não como causa eficente , ou seja, não como o sujeito cuja atividade tenha como efeito o cálice. Estes quareo modos, segundo Heidegger, são co- esponsáveis pelo deixar vir á presença a taça, no sentido grego de poíesis, produção

Com a natureza dá-se a máxima poíesis (physis), o surgir e elevar-se por si mesmo, enquanto na arte e no artesanato intervêm o artista e o artesão (téchne) ao deixar aparecer o que se oculta e não se desvela por si mesmo.

Produzir é conduzir o que está encoberto ao desencobrimento, o que os gregos chamavam de alétheia, e que traduzimos por "verdade", passando a entendêla como o correto de uma representação. No desencobrimento se funda toda a produção, que recolhe e rege os quatro modos de deixar-viger a causalidade, a cuja esfera pertence à instrumentalidade. Heidegger estabelece assim a ligação entre a essência da técnica moderna e o desencobrimento. "A técnica não é, portanto, um simples meio. A técnica é uma forma de desencobrimento" (HEIDEGGER, 2002, p. 17). Assim, mostra que a essência da técnica moderna não é neutra, ou seja, não constitui um simples meio para um fim, mas é um modo de desvelamento de sentido, de produção de verdade. Neste aspecto, se aproxima da téchne grega, porém, ao mesmo tempo, dela se distancia, por não se constituir no modo de desvelamento da poíesis, do deixar aparecer o que se oculta. A técnica moderna também é um desencobrimento, no entanto, o desencobrimento que rege a técnica moderna é uma provocação, "uma exploração que impõe à natureza a pretensão de fornecer energia, capaz de, como tal, ser beneficiada e armazenada". (HEIDEGGER, 2002, p.19). Diferente do camponês que, ao lavrar, cultivava e protegia a terra confiando no desenvolvimento das sementes sem desafiar ou 
provocar o solo no sentido de uma exploração, a agricultura, como exemplifica Heidegger, tornou-se indústria que dis-põe da natureza como matéria-prima disponível buscando dela extrair o máximo rendimento com o mínimo de gasto. Afirma Heidegger:

O desencobrimento que domina a técnica moderna possui como característica, o pôr, no sentido de explorar. Esta exploração se dá e acontece num múltiplo movimento: a energia escondida na natureza é extraída, o extraído vê-se transformado, o transformado, estocado, o estocado, distribuído, o distribuído, reprocessado. Extrair, transformar, estocar, distribuir, reprocessar são todos modos de desencobrimento (HEIDEGGER, 2002, p. 20).

No desencobrimento explorador o controle e a segurança são as marcas fundamentais.

A disponibilidade tornou-se o modo de ser dos entes na era da técnica, em lugar da objetividade cartesiana que marca a modernidade. O ente deixou de ser objeto de conhecimento para tornar-se algo sempre disposto à exploração e utilização. Heidegger (2002) utiliza o termo alemão Bestand para descrever a disponibilidade, que é mais do que uma provisão, significando o que está posto como reserva disponível para o uso. A essência da técnica moderna é caracterizada por esse modo histórico de desvelamento de sentido, que Heidegger denomina Gestell, conjunto de possibilidades do pôr enviadas ao homem, que responde ao envio como quem explora, e também como fundo de reserva disponível. Gestell é a essência da técnica moderna.

Embora o homem realize a exploração que desencobre o real como disponibilidade, não está em seu poder o desencobrimento, pois ele mesmo é desafiado pela natureza, que se desencobre como disposição, a explorá-la. De acordo com Heidegger (2002), ao ser desafiado e disposto, o homem pertence mais originariamente à disponibilidade do que a natureza, ou seja, também é desvelado neste modo histórico em sua possibilidade de ser fundo de reserva, energia disponível à exploração e uso, sem, todavia, reduzir-se jamais à mera disponibilidade.

Embora use neste ensaio uma terminologia distante daquela de Ser e Tempo, percebe-se aqui a coerência de sua interpretação com a analítica desenvolvida naquela obra: embora, de início e na maior parte das vezes, o Dasein se tome como simplesmente dado, jamais se reduz de fato a qualquer objetivação sobre si mesmo; mais que isso, somente pode tomar-se como simplesmente dado o ente cujo modo de ser é a existência.

Além de não ser um simples meio para um fim, a técnica não é também um feito do homem, que ao realizá-la, apenas participa da disposição, respondendo a um apelo do desencobrimento. Afirma Heidegger (2002, p. 22) que:

O desencobrimento já se deu, em sua propriedade, todas as vezes que o homem se sente chamado a acontecer em modos próprios de desencobrimento. Por isso, des-vendando o real, vigente com seu modo de estar no desencobrimento, o homem 
não faz senão responder ao apelo do desencobrimento, mesmo que seja para contradizê-lo.

Desencobrir o real e a si mesmo ao modo da disponibilidade constitui, para Heidegger, o destino histórico do homem, destino no sentido de "pôr a caminho", envio do Gestell, que, como essência da técnica moderna, coloca o homem no caminho do desencobrimento que conduz o real. No entanto, "o destino do desencobrimento sempre rege o homem em todo o seu ser mas nunca é a fatalidade de uma coação. Pois o homem só se torna livre num envio, fazendo-se ouvinte e não escravo do destino." (HEIDEGGER, 2002 p. 27-28). A regência parte do destino e não do homem, que a ele corresponde, podendo sempre apropriar-se tematicamente e corresponder então a outros modos históricos de desvelamento. Assim, a possibilidade de refletir sobre a essência da técnica, fazendo a experiência do Gestell como destino de um desencobrimento, permite mantermo-nos no espaço livre do destino, sem que permaneçamos na crença de que uma fatalidade nos aprisiona inexoravelmente à técnica. Daí o abrir-se à essência da técnica, como propõe Heidegger, permitir que se estabeleça com ela uma relação mais livre.

\section{Solidẽo E RELACIONAMENTO NA PERSPECTIVA}

\section{FENOMENOLÓGICO-HERMENÊUTICA}

O sentido que se dá hoje à solidão e aos relacionamentos afetivos é desvelado, ao nosso ver, segundo este modo histórico explicitado por Heidegger. Desta forma, na tentativa de aplacar a solidão e obter segurança, ora no apego ao outro que se busca controlar, ora no repúdio a qualquer comprometimento, o homem desvela a si próprio e ao outro como "fundo de reserva" disponível ao uso. Remete assim à determinação instrumental da técnica, ao desvelar-se e ao outro como meios para um fim. Da mesma forma, o desencobrir-se como uma subjetividade inacessível e fechada em si mesma, irremediavelmente apartada do mundo e do outro, são modos de resposta do homem ao desencobrimento que o desafia na era da técnica. Ao mesmo tempo, reconhecer e refletir acerca deste desencobrimento, possibilita conjurar seu maior perigo, o qual, segundo Heidegger (2002), se apresenta não nas máquinas e equipamentos técnicos, mas sim no fato de estar encoberto.

Medard Boss, psiquiatra que estabeleceu ligações entre o pensamento de Heidegger e a clínica, recorre a este texto no artigo intitulado "Solidão e comunidade". Para Boss (1976) o afastamento do mundo e do outro não é uma invenção do homem, mas sim seu destino histórico, o "espírito técnico", pelo qual o homem só apreende o mundo através de uma manipulação incessante com o objetivo de aumentar o poder do sujeito.

Boss (1976) contraria o senso comum ao afirmar que solidão e comunidade não se excluem. Define a solidão como uma forma de comunidade, pois só se pode ser sozinho tendo como referência a comunidade. Desta forma, a ausência de alguém não significa um vazio, mas um modo de sua presença, na qual pode estar bem mais próximo do que se estivesse fisicamente presente. Cita como exemplo o 
estado de luto, no qual muitas vezes aquele que morre nos parece mais próximo e presente do que quando vivo.

A idéia que fundamenta o pensamento do autor é a de que somos essencialmente e originariamente com os outros, isto é, estamos destinados à comunidade no sentido de co-pertencimento, diante de um mesmo mundo comum. Um dos modos de ser-com é a solidão, pois só pode estar sozinho quem reconhece seus semelhantes, quem os sente próximos ou distantes, ou seja, o homem. A pedra, como exemplifica Boss (1976), nunca estará só, jamais poderá experienciar a solidão.

A solidão é assim uma forma de comunidade, aqui entendida não como conjunto de indivíduos dotados de um psiquismo privado e encapsulado, apartado do mundo, idéia presente em investigações sociológicas e psicológicas que é questionada por Boss (1976). Para ele, basta olhar para o que somos e como somos, enquanto homens, para nos descobrirmos desde o início em presença dos outros, que nos aparecem desde sempre como nossos semelhantes. Esta comunidade originária se funda na relação com as mesmas coisas de um mesmo mundo comum, por serem os homens essencialmente abertura na qual a presença se manifesta, ou seja, na qual somos interpelados pela profusão de significados que se nos anunciam todo o tempo em todas as coisas do mundo. Existimos somente nesta abertura para a presença e significabilidade de tudo que nos vem ao encontro, podendo acolher e trazer à presença mesmo o que estiver mais afastado no tempo e no espaço.

Assim cada um de nós existe à sua maneira mas jamais a ponto de ser apenas para si mesmo, como se fosse primordialmente separado de todos os outros. Ao contrário, enquanto poder ser interpelado pela significabilidade do que encontra, cada um de nós participa à sua maneira da região aberta do mundo comum, na qual aquilo que vem "a ser" chega à luz de sua presença. (BOSS, 1976, p. 28).

Boss (1976) compara cada homem ao raio de sol, que, ao unir-se aos demais, forma a claridade do dia, pois juntos constituem a abertura na qual o mundo se desvela, condição para que qualquer coisa seja.

A partir desta perspectiva, pretende entender um paradoxo que considera central na modernidade, o da proximidade geográfica entre os homens e seu distanciamento existencial. Embora aproximados pelos meios técnicos de transporte e comunicação, os homens sentem-se cada vez mais isolados, estranhos entre si.

Boss (1976) diferencia afastamento e proximidade existencial da distância mensurável. O espaço geográfico deriva da espacialidade primordial da existência, ou seja, dos significados espaciais que damos ao que amamos, proximidade, ou do que nos é indiferente, o afastamento. Acabamos por atrelar estes significados, que pertencem à espacialidade existencial, à distância ou proximidade métrica, geográfica, reduzindo assim os significados espaciais a uma representação 
mensurável. A proximidade geográfica pode aproximar, mas não é suficiente, e pode mesmo distanciar. Podemos estar próximos fisicamente de alguém e experienciar ou não uma real aproximação, da mesma forma que, sozinhos, podemos ou não ter a experiência do isolamento. Porém, por esta redução, acabamos por nos sentir acompanhados apenas quando há a presença física de alguém e isolados quando ocorre o contrário. Isto explica, para Boss, o fato de os homens estarem mais sós e distantes, voltados para si mesmos, quando a distância mensurável é menor. Este distanciamento constitui, então, o modo como se dá hoje a comunidade.

Entendê-lo implica em compreender o profundo desenraizamento sofrido pelo homem na modernidade, a medida em que ele responde aos conclames que o convocam a estabelecer uma relação utilitarista com o que o cerca. Apartado da experiência coletiva, afastado dos laços que o uniam às tradições religiosas e familiares, vivendo a constante desregulamentação, o homem agora deve ocupar o espaço e o papel que anteriormente pertencia aos deuses. "Deus está morto", proclama Nietzsche; "Não precisamos mais de mitos ou de crenças, de superstições e amuletos", afirmamos todos nós. O homem coloca-se como centro, compreendese como sujeito - um amontoado de desejos, experiências, conteúdos internos. Vivemos, como conseqüência, um tempo marcado pelo intimismo, pela privatização de todos os desconfortos, o que é chamado por Guignon (1993) de "individualismo ontológico". Esse movimento caracteriza os relacionamentos humanos, percebidos a partir da experiência de um eu individual, auto-encapsulado, que encontra-se contingencialmente em um sistema social. Esta visão acaba por entender as relações sociais como, inevitavelmente, conflituosas. À medida em que nos compreendemos como indivíduos, que, baseados em um modo de pensar estratégico e calculante, devem competir pelos recursos limitados da natureza, as relações que estabelecemos acabam por se constituir em alianças estratégicas, onde o outro é visto como um aliado ou um possível obstáculo. Estas alianças são, por característica, temporárias, sendo mantidas enquanto me são convenientes, ou desde que permitam que eu me "sinta bem", ou mesmo enquanto possibilitam o meu "crescimento pessoal". As relações se constituem, então, em contratos entre dois indivíduos, sendo francamente desveladas ao modo da utilidade, ou seja, o seu sentido é o de trazer algum ganho àqueles que nelas estão envolvidos. Este modo de relacionamento marca o casamento, as amizades e as relações afetivas em geral no contemporâneo.

Vivemos, portanto, de um modo ambivalente, a busca de afastamento (ao menos daqueles que nos soam como estranhos) e a necessidade de proximidade. Aspiramos estar entre iguais, nos sentir seguros e confortáveis, amparados, e protegidos. Mas, para isso, o outro é desvelado como um "algo" colocado a nossa disposição, devendo atender aos nossos desejos, saciar a nossa "sede", dar conta do vazio que sentimos. Os nossos esforços parecem improfícuos, já que o distanciamento existencial persiste, e, mais do que isso, continuamente aprofunda-se.

Este modo de ser com o outro, no qual aquele que me cerca é desvelado como um algo a serviço de minha satisfação, é claramente restritor. Nesse fechamento existencial, negamos a possibilidade de estarmos sozinhos, acredita- 
mos precisar "encontrar alguém", aceitamos sem maiores questionamentos os conclames do contemporâneo que marcadamente vão enxergar no amor romântico a concretização da satisfação pessoal. É nesse contexto que a solidão é vivida enquanto sofrimento, pois mesmo estando próximos, não nos sentimos, de fato, junto ao outro.

A personagem Grete Samsa, da novela "A Metamorfose" de Kafka (2002), é emblemática deste movimento: enquanto o irmão, Gregor, trancado em seu quarto, metamorfoseava-se em inseto, Samsa progressivamente o transformava de "ele" para "isso". Desvelado enquanto coisa, Gregor devia ser descartado, converterase em estranho, e, agora, só trazia inquietação e angústia. Na verdade, Gregor sempre fora um "isso", um isso que recebera um nome, que era reconhecido como um ele, como o irmão, somente enquanto se mantivera, adequadamente, no papel que as relações sociais exigiam - o reconhecimento do espelho, o espelho de Samsa que só via no outro um algo para satisfação do "si mesma".

Para Boss, entretanto, é possível nos abrirmos para outros modos de relação com o mundo e com o outro. Para isso, será necessário sair da visão do sujeito que exerce sua vontade possessiva de forma absoluta, a fim de possibilitar ser aquilo que se apresenta, ou seja, tornarmo-nos mais disponíveis ao compreendermos que "o domínio técnico sobre o mundo realiza apenas uma única possibilidade entre muitas outras da presença do mundo [...]”. (BOSS, 1976, p. 41).

\section{SOLIDÃo, ANGÚSTIA E REFLEX̃̃o PSICOTERÁPICA}

O modo histórico de desvelamento descrito acima cria um paradoxo: o homem desvelado enquanto sujeito, interioridade, mônada, é convocado a estabelecer uma relação de dominação e controle sobre o mundo e sobre os outros. Cabelhe ser vitorioso, conquistar pessoas e afetos. Assim sendo produz-se um desenraizamento no qual a sua experiência de ser-com o outro se oculta, em que ele se vê como um frente ao mundo. Esse modo de comunidade é experimentado enquanto solidão - mesmo estando próximo ele vive o apartamento, o distanciamento existencial. Precisa do outro mas vai buscá-lo enquanto "algo" para minorar a sua solidão. O outro então torna-se "isso", um objeto a serviço das aspirações do sujeito. Nesse modo de ser-com o outro, entretanto, a solidão se agudiza e é neutralizada, apenas momentaneamente, enquanto o outro encontra-se à disposição, durante o tempo em que ele "serve" para aplacá-la. O desenraizamento produzido pela modernidade, portanto, fomenta a solidão. Levando os homens a se buscarem uns aos outros, eles o fazem, no entanto, tomando a si mesmos e aos outros como individualidades contingencialmente dispostas no mundo, como se fossem entes cujo modo de ser fosse simplesmente dado e não como existentes. Esse movimento, por outro lado, acaba por acirrar o desenraizamento e o conseqüente afastamento existencial.

Heidegger (1989), no entanto, nos fala da possibilidade de um outro modo de correspondência frente aos sentidos que nos interpelam. Sendo assim, ao caracterizarmos o ente que nós mesmos somos, essencialmente, enquanto cuidado (sorge), afirmamos uma dimensão de co-pertencimento originário com o outro. 
Isto porque ser-com não significa somente que estamos em constante relação com os outros entes no mundo, mas muito mais do que isto, o próprio acontecimento de sermos implica o acontecimento do outro, já que somos co-originariamente com o mundo, e por conseqüência co-originariamente com os outros entes. A rigor o próprio termo relação tem as suas limitações, sendo usado muito mais por uma limitação lingüística, afinal, falarmos em uma relação implica em nos referirmos a dois entes que, em um dado momento, encontram-se em uma condição de "não relação" e que se colocam, circunstancialmente, um ao lado do outro, em "relacionamento". Mas não existe a possibilidade de existirmos de um modo "solipse" e eventualmente nos colocarmos em relação; existir, já é, essencialmente, ser-com. Dentro desse horizonte compreensivo, a solidão existencial, não implica, necessariamente, em um vazio a ser preenchido, mas, pode sim, se constituir em um afastamento que possibilita o encontro "consigo mesmo", com os nossos projetos e aspirações singulares. Esse encontro, por outro lado, faz-se possível e tolerável pois o "si-mesmo", aí desvelado, não é uma cápsula irremissivelmente afastada do mundo, mas o ser-com o outro, em constante co-pertencimento com os outros. É possível, desta forma, ouvir o silêncio e o clamor da angústia, sem que isto implique em uma experiência de desenraizamento. O que significa dizer que o próprio nada a que a angústia me conclama - a possibilidade de vir a ser - será sempre um vir a ser com-o-outro-no-mundo.

O filme Edifício Master (2002), dirigido por Eduardo Coutinho, mostra de forma paradigmática a solidão do homem médio contemporâneo. O contraste entre a aglomeração física de seres humanos, num edifício com centenas de pequenos apartamentos conjugados num bairro de máxima densidade demográfica como Copacabana, e a experiência de profunda solidão e ausência de enraizamento comunitário é tão gritante que não há necessidade de nenhuma análise fenomenológica para se fazer a experiência da radical diferença entre supressão da extensão de distância e proximidade. Fugimos da solidão, ou pelo menos tentamos, usando todos os frágeis recursos que nos são possíveis. Tal fuga é compreensível e justa, afinal a solidão abre o vazio no qual a angústia está sempre à espreita. Junto à solidão encontraríamos toda a nossa fragilidade, indigência, finitude, nosso serpara-a-morte. Mas muitas vezes, se não quase sempre, pagamos um preço demasiadamente alto por esse desvio. Pior, parece que a dívida sempre aumenta e temos que continuar pagando cada vez mais. Pagamos com algo que nos é essencial, nossa capacidade de ver, de corresponder à realidade em suas múltiplas e misteriosas possibilidades de sentido. Pois, para eludir a solidão temos que nos esquivar de tudo aquilo que somos num sentido mais próprio. A solidão existencial não é um estado mórbido ou patológico, nem um problema circunstancial a ser resolvido pela conquista de relacionamentos seguros. Apenas no silêncio da hora mais solitária, quando se cala o alarido impessoal dos desejos e representações correntes de "todo mundo", é que podemos nos pôr à escuta das demandas e dos questionamentos de sentido que nos são mais próprios e singulares.

O encontro psicoterápico poderá facilitar tal reflexão. Nele seremos muitas vezes conclamados a dar conta da solidão daqueles que nos buscam. Isso se faz presente na fala dos que nos procuram com o objetivo de resolver as suas dificul- 
dades de relacionamento. Expressam o desejo de "trabalharem" as suas características que, acreditam, os impedem de manterem relações estáveis, ou afirmam não tolerar a solidão em que vivem, seja porque não têm um parceiro afetivo ou porque vivem o afastamento existencial na intimidade da relação.

Frente às considerações que anteriormente fizemos, nos parece estar suficientemente claro que o papel que nos cabe, dentro da perspectiva que adotamos, não será o de simplesmente ajustarmos aquele que nos buscam aos ditames da medianidade a fim de que ele consiga encontrar o sonhado parceiro amoroso. $\mathrm{O}$ encontro propiciado pela clínica poderá, de outro modo, colocar-se como um espaço de reflexão e tematização deste modo histórico de desvelamento, ou seja, um espaço para "meditar".

O pensamento meditante é apontado por Heidegger (2000), em um texto intitulado Gelassenheit, traduzido para o francês como Sérénité, como aquele que se coloca como alternativa ao pensamento "calculante". Este é o pensamento dominante, representacional, que provoca a natureza a se desvelar enquanto "objeto" passível de ser calculado. Esta forma de pensar, chamada por Heidegger de "indigência do pensamento", tende ao empobrecimento do pensamento, colocando em perigo a própria essência humana, à medida que põe em risco a possibilidade de pensar. Apoiando-se na sua capacidade de atingir resultados considerados "práticos", tais como as inquestionáveis conquistas alcançadas pelas pesquisas tecnológicas, este modo de pensar calculante avança, progressivamente, com pretensões de tornar-se o único modo legítimo de pensar. Já o pensamento meditante, ao invés de pretender a aproximação com o real através do horizonte do cálculo, propõe um novo enraizamento. Isto porque as raízes sobre as quais se situava a nossa civilização, foram definitivamente destruídas pela era tecnológica, que afastou o homem de suas referências ancestrais, à medida que o aproximou de uma única forma de compreensão do real, baseada no desejo de controle e na possibilidade de mensuração. Como afirma Heidegger:

O pensamento meditante exige de nós que não nos fixemos sobre um só aspecto das coisas, que não sejamos prisioneiros de uma representação, que não nos lancemos dentro de uma única via, dentro de uma só direção. O pensamento meditante exige de nós que aceitemos nos deter sobre as coisas que à primeira vista parecem irreconciliáveis. (HEIDEGGER, 2000, p. 144).

O espaço da clínica, dentro da perspectiva que trabalhamos, não deixa de ser, portanto, um espaço de meditação, entendida aí como a abertura a outros modos de pensar, a uma reflexão que se afaste de uma linguagem hegemônica, técnico-calculante, que se constitui no modo de pensamento da medianidade.

Como "destino", o modo de pensar calculante não é algo a ser vencido. Essa tarefa, em verdade, nos parece improfícua, já que, estando imersos em um horizonte de sentidos e significados já dados mundo, a experiência de ser na modernidade já envolve, de algum modo, pensar calculantemente. O meditar, no entanto, nos permite um "nos darmos conta": a possibilidade de percebermos o 
jogo histórico que constitui aquilo que somos, que desvela os nossos desejos, sonhos e formas de nos relacionarmos, de um modo instrumental, utilitarista e privatizante. Esse "se dar conta" é o campo de liberdade que nos é possível, não uma liberdade absoluta de um sujeito que escolhe o seu destino, mas a do ouvinte que se abre a outras possibilidades de interpelação frente ao que o confronta.

O papel do psicoterapeuta não será o de um operador que, através dos seus recursos técnicos, produzirá a mudança necessária no paciente, a fim de que ele tenha melhores relacionamentos afetivos, ou que possa superar a sua solidão. Ao invés disso, como um facilitador, o clínico abrirá um canal compreensivo - hermenêutico, reflexivo, de meditação - em que as experiências singulares daquele que se angustia possam vir à luz, articuladas com o horizonte histórico que as constitui.

Esse movimento não terá um objetivo único - a superação da solidão -, embora ela possa efetivamente ocorrer. Outros caminhos também serão possíveis, como por exemplo, o paciente se dar conta de que a necessidade de encontrar um parceiro amoroso, como se isso fosse um distintivo de seu sucesso enquanto pessoa, não atende, de modo mais próprio, as suas necessidades de sentido. Outras pessoas, por outro lado, poderão aprender a lidar com a sua solidão e mesmo valorizá-la, como um outro modo de relacionar-se com aquilo que as cerca.

O psicoterapeuta, enquanto aquele que vela por esse espaço de meditação, deve suportar o paradoxo, a ambivalência, a sua própria impotência. Somente colocando-se também como um ouvinte, atento aos apelos históricos que o convidam a ver o sofrimento como um defeito e a si mesmo como um técnico capaz de corrigí-lo, ele pode abrir canais efetivos de comunicação com a experiência existencial daquele que o procura, permitindo que ele e o paciente se vejam lançados, a partir da relação terapêutica, para outras possibilidades de ser no mundo.

\section{REFERÊNCIAS}

BOSS, M. Solidão e comunidade. Revista da Associação Brasileira de Daseinsanalyse, São Paulo, n. 2, p. 25-45, 1976.

GUIGNON, C. (Org.). Authenticity, moral values, and psychotherapy. In: The Cambridge Companion to Heidegger. Cambridge: Cambridge University Press, 1993.

HEIDEGGER, M. A questão da técnica. In: . Ensaios e conferências. Petrópolis: Vozes, 2002. . Ser e tempo. Petrópolis: Vozes, 1989. v. I e v. II, Sérénité. In : . Question III et IV. Paris: Éditions Gallimard, 2000.

KAFKA, F. A metamorfose. São Paulo: Nova Cultural, 2002.

RILKE, R. M. Cartas a um jovem poeta. São Paulo: Globo, 1989.

YALOM, I. D. O executor do amor. Porto Alegre: Artes Médicas, 1996. 
Roberto Novaes de Sá, Cristine Monteiro Mattar e Joelson Tavares Rodrigues

EDIFÍCIO Master. Direção: Eduardo Coutinho. Produção: Maurício Andrade Ramos e João Moreira Salles. [S.1.]: Videofilmes; Riofilme, 2002. 1 DVD (110 min.)

Recebido em: julho/ 2005. Aceito em: Novembro/ 2005. 